\title{
The LIM-Only Protein Four and a Half LIM Domain Protein 2 Attenuates Development of Psoriatic Arthritis by Blocking Adam17-Mediated Tumor Necrosis Factor Release
}

Rafael Leite Dantas, ${ }^{*}$ Bent Brachvogel, ${ }^{\dagger}$ Tanja Schied, ${ }^{*}$ Vera Bergmeier, ${ }^{\dagger}$ Boris Skryabin, ${ }^{\S}$ Thomas Vogl, ${ }^{ø}$ Stephan Ludwig, ${ }^{*}$ and Viktor Wixler*

From the Institutes of Virology* and Immunology and the Department of Medicine (TRAM), ${ }^{\S}$ Westfaelische Wilhelms University, Muenster; the Department of Pediatrics and Adolescent Medicine, ${ }^{\dagger}$ University Hospital of Cologne, Cologne; and the Center for Biochemistry, ${ }^{\ddagger}$ Medical Faculty, University of Cologne, Cologne, Germany

Accepted for publication July 26, 2017.

Address correspondence to Viktor Wixler, Ph.D., Institute of Virology, Westfaelische Wilhelms University, VonEsmarch-Strasse 56, 48149 Muenster, Germany. E-mail: vwixler@uni-muenster.de.

\begin{abstract}
Four and a half LIM domain protein 2 (Fhl2) is an intracellular adaptor molecule with a high proteinprotein interaction capacity. It acts as a modulator of several signaling molecules in the cytosol and as a cofactor of transcription in the nucleus. Recent studies suggest the role of Fhl2 in tissue repair and the anti-inflammatory response. Herein, we show that Fhl2-deficient mice develop a more severe psoriatic arthritis disease under induction of the inducible human tumor necrosis factor (hTNF) transgene than wild-type mice. The disease was accompanied by increased infiltration of activated macrophages and T regulatory cells in skin and digit joints as well as by increased expression of matrix metalloproteases and bone-specific proteases. The more severe pathogenesis of psoriatic arthritis in Fhl2 knockout mice coincided with enhanced levels of soluble hTNF cytokine, but surprisingly not with transcription of the hTNF transgene. Studying the shedding of cell membrane-bound hTNF by Adam17, a known Fhl2 interacting protein, revealed an enhanced release of TNF in the absence of Fhl2. In summary, our results show that Fhl2 anticipates the emerging inflammation and specifically the development of psoriatic arthritis by impeding the Adam17-mediated release of TNF. (Am J Pathol 2017, 187: 2388-2398; $h t t p: / / d x . d o i . o r g / 10.1016 / j$.ajpath.2017.07.015)
\end{abstract}

Autoimmune diseases, like psoriasis or arthritis, are driven by an interplay of many biological processes, the particular activity of which is forced by differential gene expression. One of the most eminent genes is tumor necrosis factor- $\alpha(T N F)$, the pathological up-regulation of which results in severe immune effects. ${ }^{1} \mathrm{TNF}$, in turn, affects, either positively or negatively, the activity of other genes that regulate both proinflammatory and anti-inflammatory events. Recently, we showed that prolonged stimulation of synovial fibroblasts with TNF down-regulates the four and a half LIM domain protein 2 (Fhl2), ${ }^{2,3}$ thereby facilitating expression of matrix metalloproteases (MMPs) and enhanced tissue destruction. ${ }^{4}$ This work indicated that Fhl2 has a distinct antiinflammatory activity. Other reports showed that Fhl2 attenuates lung inflammation during fibrosis or asthma $a^{5,6}$ and supports wound healing after skin, liver, or intestine injury. ${ }^{7-9}$ Furthermore, deletion of the Fhl2 gene impairs inflammatory reaction and scar formation after cardiac ischemia $^{10}$ and attenuates neovascularization after corneal injury. ${ }^{11}$ These observations, along with data showing that Fhl2 regulates the assembly of extracellular matrix and migration of fibroblasts and dendritic cells, ${ }^{9,12,13}$ prompted us to study the impact of Fhl2 in the development of autoimmune diseases. Thus, we induced a proinflammatory reaction in Fhl2-deficient mice using our recently established

Supported by Coordination for the Improvement of Higher Education Personnel Brazil grant 99999.013234/2013-07 (R.L.D.) and the German Research Foundation grants SFB 492 A17 (V.W.) and SFB 1009 B08 (S.L.).

Disclosures: None declared. 
doxycycline (Dox)-inducible human $T N F$-transgenic mouse line that develops a psoriatic arthritis-like phenotype under Dox stimulation, ${ }^{14,15}$ and then studied the inflammatory response in skin and joint tissues. Our data support the assumption that $\mathrm{Fhl} 2$ is an anti-inflammatory protein and further demonstrate that Fhl2 prevents the development of psoriatic arthritis by blocking the Adam17-mediated cleavage of membrane-bound TNF- $\alpha$.

\section{Materials and Methods}

Animals

All animal experiments were approved by the local ethics committee and performed in strict accordance with the German regulations of the Society for Laboratory Animal Science and the European Health Law of the Federation of Laboratory Animal Science Associations. The protocols were approved by the North Rhine-Westphalia State Agency for Nature, Environment, and Consumer Protection (LANUV-NRW; Recklinghausen, Germany).

The details of inducible ihTNFtg mouse generation were published recently. ${ }^{14,15}$ These mice contained two transgenes: the modified reverse tet transactivator rtTA2S-M2, published by Katsantoni et al, ${ }^{16}$ and the full-length human TNFalpha cDNA (https://www.ncbi.nlm.nih.gov/nuccorel 395132451; accession number NM_000594), cloned behind the Tet-responsive P-tight promoter in the plasmid pTRETight (BD Biosciences Clontech, Heidelberg, Germany). The $3^{\prime}$-untranslated region of $T N F$ was replaced by the SV40 Poly A site, to avoid post-transcriptional regulation. The mice expressed the human TNF cytokine only after doxycycline administration. By crossing them with $F h l 2^{-/-}$ mice, the ihTNFtg/Fhl2 ${ }^{K O}$ animals homozygous for rtTA2S$M 2, h T N F$ transgenes and for mutated $F h l 2$ locus were obtained. To induce the expression of the $h T N F \alpha$ transgene, mice were provided drinking water containing 1 $\mathrm{mg} / \mathrm{mL}$ doxycycline (Sigma, Taufenkichen, Germany) for 21 days. The major source of human TNF (hTNF) in these mice is keratinocytes and, to a lesser extent, macrophages and dendritic cells, but not granulocytes or lymphocytes. ${ }^{14}$

\section{Histology and Disease Assessment}

Skin and forepaw specimens were fixed in $4 \%$ paraformaldehyde for 2 hours and overnight, respectively, and after dehydration were embedded in paraffin. Paws were decalcified with $0.5 \mathrm{~mol} / \mathrm{L}$ EDTA solution for approximately 3 weeks before embedding. Tissue sections $(4 \mu \mathrm{m}$ thick) were analyzed. For X-Gal staining, paws of mice were fixed in acetone overnight at $4^{\circ} \mathrm{C}$ and incubated in $\mathrm{X}$ Gal solution for 8 hours at $37^{\circ} \mathrm{C}$. After overnight incubation in $4 \%$ paraformaldehyde, they were rapidly decalcified with $0.1 \mathrm{~mol} / \mathrm{L}$ EDTA during 6 days at $42^{\circ} \mathrm{C}$, dehydrated, and embedded in paraffin. ${ }^{17}$ To allow a better penetration of the $\mathrm{X}-\mathrm{Gal}$ solution into the tissue, the skin of digits was cut.
Using a grading scale of 0 to 7 , the psoriasis area and severity index (PASI) was determined separately for five different areas: head, neck, back, throat, and abdominal areas. Then, the severity of the affected area, including hair loss, erythema, scaling, and thickening, was considered. The sum of the five area scores (scale, 0 to 35) represented the final psoriasis area and severity index per mouse. ${ }^{14}$ Epidermal thickness was evaluated using hematoxylin and eosin-stained skin samples and AxioVision software version 4.8.2.0 (Carl Zeiss AG, Oberkochen, Germany). A total length of 1000 to $3000 \mu \mathrm{m}$ of each skin specimen was scored, and mean values of measurements that have been performed each $50 \mu \mathrm{m}$ were taken.

The extent of inflammation and cartilage damage in the paws was determined by morphometry, as described elsewhere. ${ }^{15}$ Usually, four different sections per mouse sample and five to seven mice per case were quantified. The inflamed area was defined as the infiltrated tissue area and was assessed in relation to the total tissue area [in toes, the area from the apex of a toe to the proximal tendon basis of the distal interphalangeal (DIP) joints was defined as the total area].

Disease assessments were performed in a blinded manner by R.L.D., T.S., and V.W.

\section{Analysis of Skin and Paw Immune Microenvironment}

Single-cell suspensions of skin and paws were obtained by enzymatic digestion with $3.2 \mathrm{mg} / \mathrm{mL}$ collagenase type I, $0.417 \mathrm{mg} / \mathrm{mL}$ liberase TL, and $1 \mathrm{mg} / \mathrm{mL}$ DNase I. Enzymes were added to Dulbecco's modified Eagle's medium plus $5 \%$ fetal calf serum, and tissue samples were digested at $37^{\circ} \mathrm{C}$ for 1.25 and 1 hour. Samples were passed through a filter cartridge to remove large pieces of tissue and washed with phosphate-buffered saline plus 5\% fetal calf serum. The most antibodies used in flow cytometry analysis were from eBioscience (Frankfurt, Germany) and were routinely used at concentrations of 0.5 to $1.5 \mu \mathrm{g} / \mathrm{mL}$, as previously described. ${ }^{14}$ After cell fixation and permeabilization, intracellular staining for Foxp3 was performed using the Foxp3/ Transcription Factor Staining Kit (eBioscience), according to the manufacturer's instructions.

During generation of $F h l 2^{K O}$ mice, part of exon 2, including the translation initiation codon ATG, of the Fhl2 allele was replaced with a LacZ reporter gene and a neo resistance cassette. ${ }^{18}$ Thus, in some experiments, the presence of the LacZ determining the $\beta$-galactosidase enzyme was used by us for determining FHL2-positive immune cells. Freshly isolated skin cells from $i h T N F t g / F h l 2^{K O}$ mice were kept at $37^{\circ} \mathrm{C}$, and $100 \mu \mathrm{L}$ of cell suspension in phosphate-buffered saline plus $5 \%$ fetal calf serum was mixed with $100 \mu \mathrm{L}$ of prewarmed $1 \mathrm{mmol} / \mathrm{L}$ fluorescein di- $\beta$-D-galactopyranoside (Sigma-Aldrich, St. Louis, MO) and incubated for $10 \mathrm{mi}-$ nutes. The number of fluorescein isothiocyanate-positive cells was verified by flow cytometry. Fluorescein di$\beta$-D-galactopyranoside is one of the most sensitive substrates 
for $\beta$-galactosidase and is hydrolyzed by the enzyme to the fluorescence product fluorescein isothiocyanate.

\section{Quantitative Real-Time RT-PCR}

Skin or forepaw samples were minced and immediately transferred into RNAlater solution. After overnight incubation at $4^{\circ} \mathrm{C}$, they were homogenized and the RNA was isolated using an RNeasy kit (Qiagen, Hilden, Germany). RNA integrity was assessed using an Agilent Bioanalyzer 2100 (Agilent Technologies, Böblingen, Germany), and the RNA was reverse transcribed into cDNA using the high-capacity cDNA reverse transcription kit from Applied Biosystems (Darmstadt, Germany). The relative levels of mRNA were determined by TaqMan quantitative real-time PCR using the LightCycler 480 II (Roche Diagnostics, Mannheim, Germany). Each cDNA sample was analyzed in triplicate, and specific signals were scored in relation to the signals of two reference transcripts (Gapdh and $C y c s$ ). The results from different experiments were normalized to the expression of a calibrator sample, which was applied as a positive control in each experiment. The primers used were assigned using the Universal ProbeLibrary Assay Design Center of Roche Diagnostics.

\section{Determination of Soluble Cytokines}

The amount of human or mouse TNF cytokines and mouse S100A8/A9 proteins in the serum of mice was analyzed by conventional enzyme-linked immunosorbent assay, as described previously. ${ }^{15}$ The concentration of IL-1 $\beta$, IL-2, IL-4, IL-5, IL-6, IL-10, IL-12, IL-13, IL-17A, interferon- $\gamma$, TNF- $\alpha$, and granulocyte-macrophage colony-stimulating factor in sera was measured by LUNARISTM Mouse 12-Plex Cytokine Kit384 and LUNARISTM Analysis Suite software version 1.0.1 from AYOXXA Biosystems (Cologne, Germany; catalog numbers LMC-20121S and LAS-001, respectively), and the concentration of chemokine (C-C motif) ligand (CCL) 2 was measured by LEGENDplex flow-based 13-plex mouse inflammation panel kit from Biolegend (Fell, Germany; catalog number 740150).

\section{Inhibition of Adam17}

The role of Fhl2 in ADAM17-mediated shedding of surface hTNF was studied in primary keratinocytes, as these cells express the highest amount of recombinant hTNF. Keratinocytes were isolated from untreated control ihTNFtg or ihTNFtg/Fhl $2^{K O}$ mice. Skin specimens were incubated in $0.25 \%$ trypsin-EDTA solution as floating tissue pieces at $4{ }^{\circ} \mathrm{C}$ for 11 hours. Afterward, the epidermis was separated from the dermis, cut into small pieces, and suspended in KBM-Gold medium (Lonza, Cologne, Germany; catalog number 195130). After passing through a cell strainer $(70 \mu \mathrm{m})$, cells were pelleted at $300 \times g$ for 7 minutes and resuspended in Eagle's minimal essential medium (Lonza; catalog number BE06-174G). Obtained cells were incubated in 24-well plates in $0.5 \mathrm{~mL}$ tissue culture medium plus $5 \%$ fetal calf serum with $10^{6}$ cells per well for 4 hours. To induce human TNF expression, cells were stimulated during these 4-hour incubations with $20 \mu \mathrm{g} / \mathrm{mL}$ Dox. To prevent the shedding of newly synthesized TNF, keratinocytes were cultured in the presence of different concentrations of ADAM17 inhibitor TMI-1 (Tocris Bioscience, Wiesbaden-Nordenstadt, Germany; catalog number 5960). ${ }^{19}$ Subsequently, cells were resuspended, stained for surface-expressed human TNF and cytosolic pan-keratin, and analyzed by flow cytometry.

\section{Statistical Analysis}

Data are expressed as the means \pm SEM. Statistical analysis was performed using either the $U$-test or the one-way analysis of variance, followed by the Newman-Keuls test. GraphPad Prism software version 7.0 (GraphPad Inc., San Diego, CA) was used.

\section{Results}

Fhl2 Deficiency Exacerbates the TNF-Mediated Psoriatic Arthritis

To elucidate the potential anti-inflammatory activity of Fhl2, homozygous ihTNFtg and ihTNFtg/Fhl2 ${ }^{K O}$ mice were stimulated for 3 weeks with Dox to induce psoriatic arthritis. On Dox stimulation, transgenic ihTNFtg mice expressed high levels of human TNF, causing inflammation of the skin and toes. Particularly strongly affected tissues were the skin of the head and neck and DIP joints. ${ }^{14,15}$ Scoring Fhl2-deficient and wild-type mice for body weight loss during Dox stimulation (Supplemental Figure S1) or skin lesions according to psoriasis area and severity index (Figure 1A) showed significantly more enhanced disease in ihTNFtg/Fhl2 ${ }^{K O}$ than in ihTNFtg mice. Also, histological analyses of skin (Figure 1, A and C) or DIP joint (Figure 1, B and D) sections at day 21 of Dox stimulation confirmed the more severe pathology of both skin and finger joints. The epidermal thickness of the skin and cartilage alteration of DIP joints were significantly enhanced in ihTNFtg/Fhl2 ${ }^{K O}$ mice compared with ihTNFtg mice. The same was true for inflamed areas and formation of pannuslike tissues in DIP joint structures (Figure 1, B and D, and Supplemental Figure S2).

\section{Immunological Status of the Inflamed Skin and Paws}

To gain a deeper insight into the process of ongoing inflammation in the skin and DIP joints of ihTNFtg and ihTNFtg/Fhl2 ${ }^{K O}$ mice and to explore whether the pattern of inflammatory infiltrates in the two organs is similar or not, single-cell suspensions were isolated from skin and paws by enzymatic digestion and analyzed for different sets of immune cells by flow cytometry. Disease-affected mice had received Dox for 21 days before analysis. Non-treated mice were used as controls. The obtained results (Figure 2) are 
A

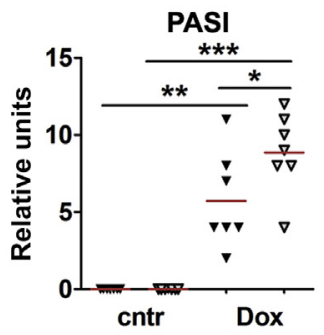

Skin

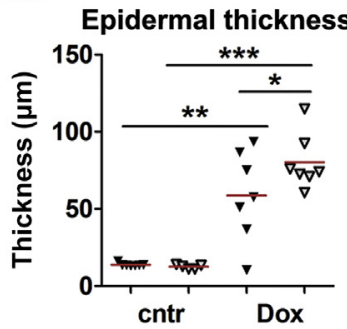

B

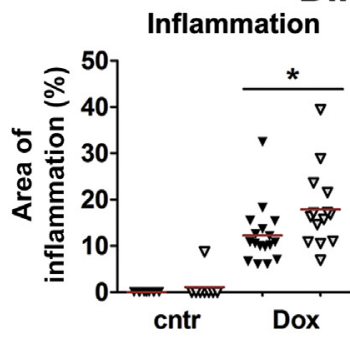

D

Dox
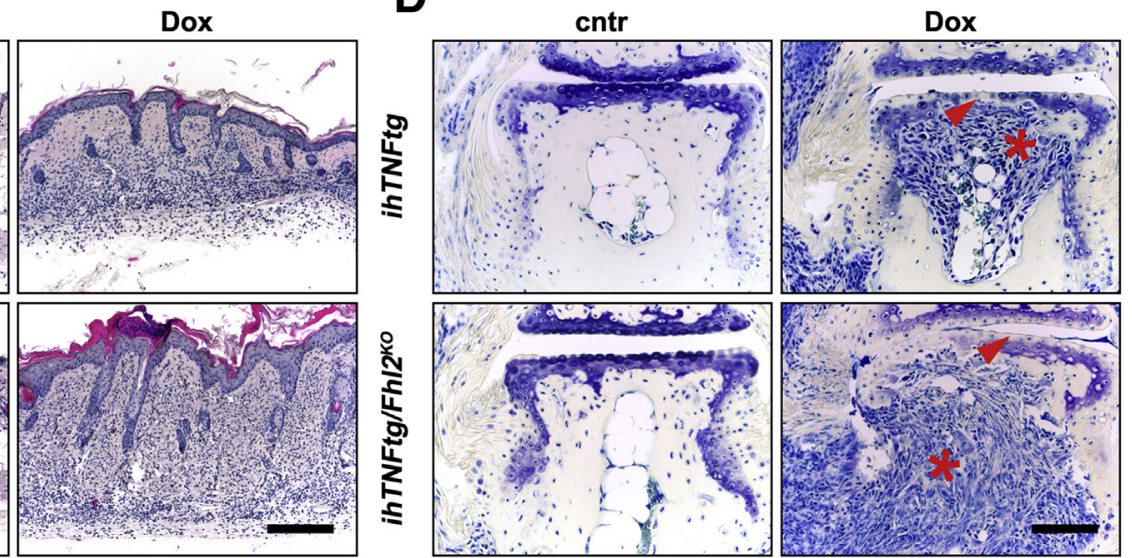

Figure 1 Deficiency in Fhl2 exacerbates the tumor necrosis factor (TNF)-mediated psoriatic arthritis. Six-month-old ihTNFtg and ihTNFtg/Fhl2 ${ }^{K O}$ animals were left untreated (cntr) or received $1 \mathrm{mg} / \mathrm{mL}$ doxycycline (Dox) with drinking water for 3 weeks, and the severity of developed psoriasis (Skin) and arthritis of distal interphalangeal (DIP) joints were scored. A: The psoriasis area and severity index (PASI; left panel) and the mean epidermal thickness (right panel) of individual mice. B: Inflammation (left panel) and cartilage destaining (right panel) values of individual mice. Mean values of four phalanges for each mouse are shown. C: Hematoxylin and eosin images of cntr and Dox-treated mouse skin. D: Toluidine blue images of distal interphalangeal joints. Note the invasion of pannus-like tissue into bone (asterisks) and cartilage destaining (arrowheads). Mean values per group are shown (red lines). Statistical analysis was performed using one-way analysis of variance, followed by the Newman-Keuls test. ${ }^{*} P<0.05,{ }^{*} P<0.01$, and ${ }^{* * * P} P 0.001$. Scale bars: $200 \mu \mathrm{m}(\mathrm{C})$; $100 \mu \mathrm{m}$ (D).

particularly interesting in two respects. First, both skin and DIP joints of ihTNFtg/Fhl2 ${ }^{\text {KO }}$ mice always showed a significantly stronger infiltration with activated macrophages and $\mathrm{T}$ regulatory cells (Tregs) than ihTNFtg mice. Second, the pattern of immune cells infiltrating into affected skin and into DIP joints in mice with psoriatic arthritis was similar, independently of the mouse line analyzed. Generally, the fact that ihTNFtg and ihTNFtg/Fhl2 ${ }^{K O}$ mice responded to Dox-mediated TNF stimulation with increased infiltration of macrophages and Tregs is in accordance with our previous data showing that TNF-mediated psoriasis is mainly determined by macrophages and that their proinflammatory activity is concurrently limited by TNF-induced Tregs. ${ }^{14}$ However, in ihTNFtg/Fhl2 ${ }^{K O}$ mice, an increased ratio of $\mathrm{CD}^{+}{ }^{+} \mathrm{Foxp}^{+}$Tregs was always measured (Figure 2). Furthermore, the number of monocytes $\left(\mathrm{CD} 11 \mathrm{~b}^{+}\right.$ cells) and macrophages $\left(\mathrm{CD} 11 \mathrm{~b}^{+} \mathrm{F} 4 / 80^{+}\right.$cells), including activated macrophages $\left(\mathrm{CD}_{11} \mathrm{~b}^{+} \mathrm{MHCII}^{+}\right)$, was also increased in the inflamed skin and paws of $i h T N F t g / F h l 2^{K O}$ mice when compared with ihTNFtg animals. The number of dendritic cells (represented by $\mathrm{CD} 11 \mathrm{c}^{+}$cells) and neutrophils (represented by $\mathrm{CD} 11 b^{+} \mathrm{Ly}_{6} \mathrm{G}^{+}$cells) was also higher in ihTNFtg/Fhl2 ${ }^{K O}$ mice, but the increase was not as prominent as it was observed for the macrophage population. Altogether, these results show that ihTNFtg/Fhl2 ${ }^{\text {KO }}$ mice respond to TNF induction with increased infiltration of both skin and DIP joints with macrophages and Tregs.

\section{Cytokine and Protease Status of the Inflamed Skin and Paws}

Inflammatory diseases are accompanied by activation of diverse genes, including genes coding for cytokines and chemokines, but also for proteases that are ultimately responsible for infiltration of affected tissues by immune cells and for tissue damage. The expression profile of a specific set of genes commonly associated with psoriatic diseases was analyzed in the skin and DIP joints after Dox treatment. First, we studied the expression of Fhl2 itself. Its transcriptional activity, both in the skin and in DIP joints, was significantly down-regulated on TNF induction (Figure 3, A and B). Interestingly, the detection of $\beta$-galactosidase enzyme activity of the expressed reporter gene within the targeted Fhl2 locus, by hydrolysis of either 
A

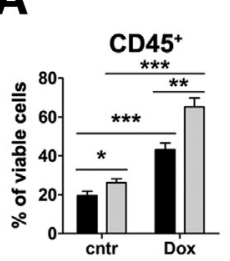

CD11c $^{+}$

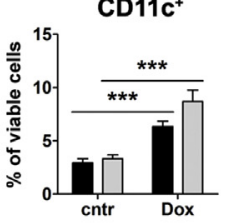

CD11b+F4/80

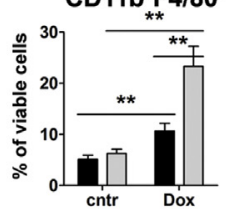

C
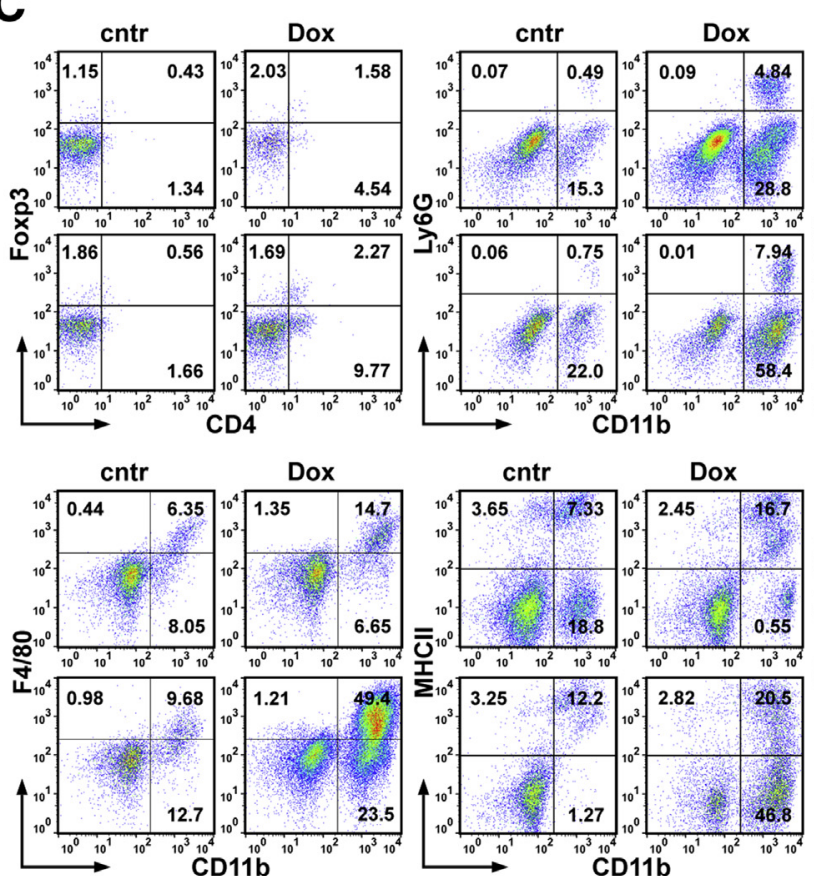

B

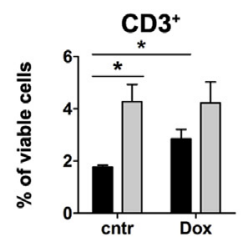

CD11c ${ }^{+}$

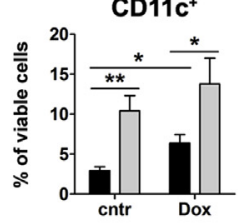

CD11b+F4/80
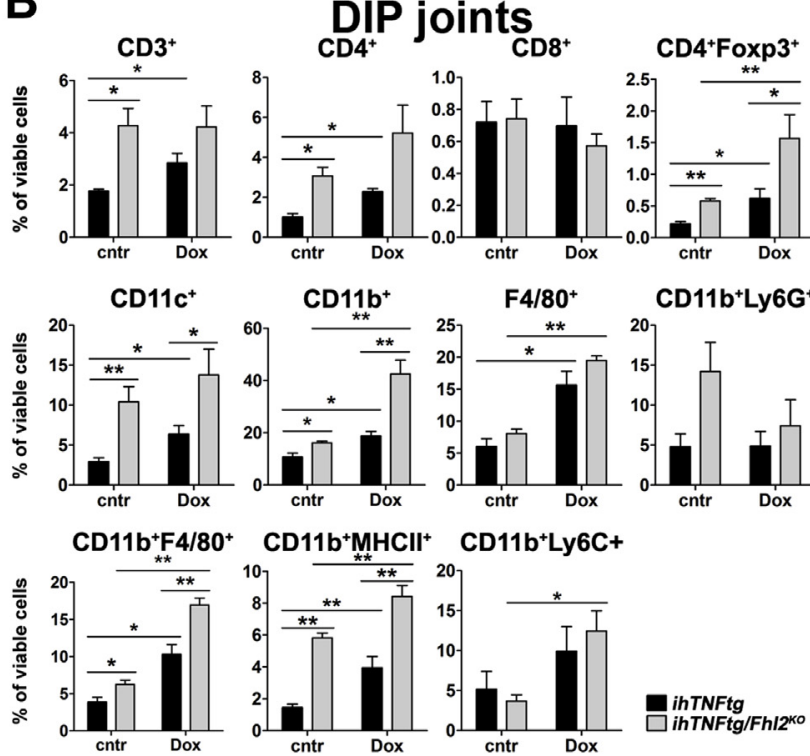

$\mathrm{CD}^{11 b^{+}}$

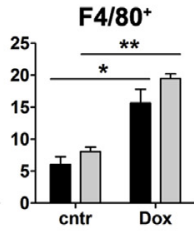

CD11b+Ly6G ${ }^{+}$

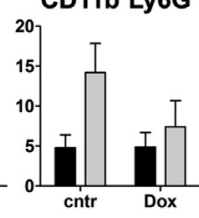

CD11b+MHCII+ CD11b+Ly6C+
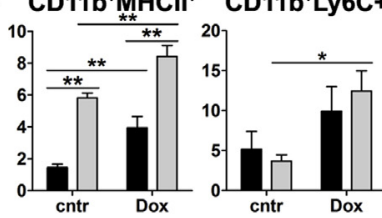

ihTNFtg

D
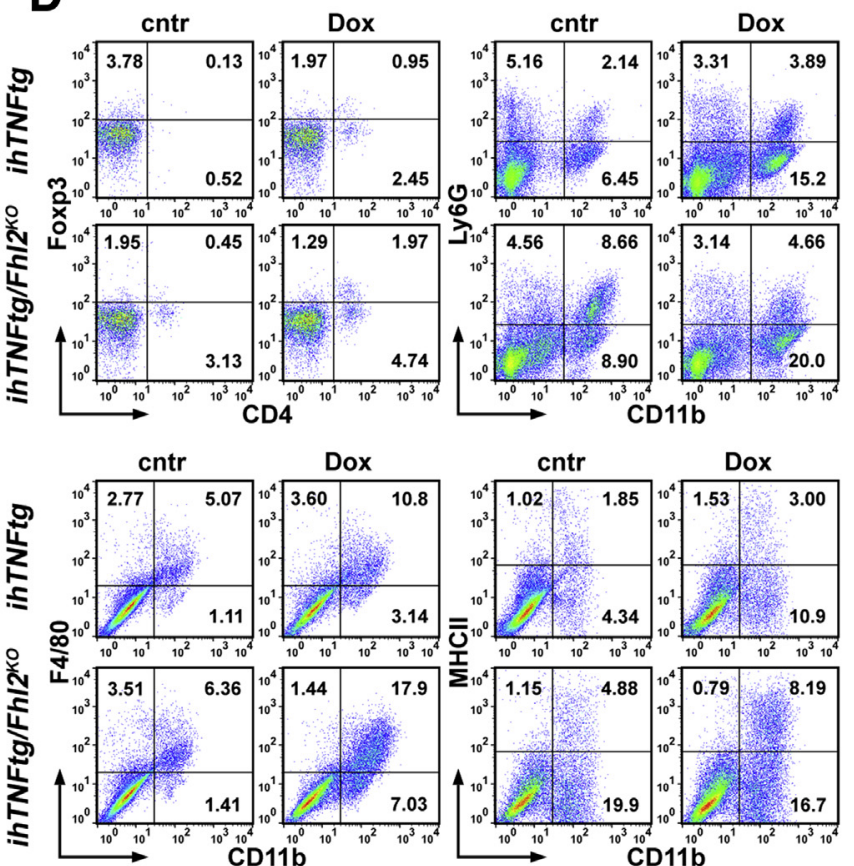

Figure 2 Immunological status of ihTNFtg and ihTNFtg/Fhl2 ${ }^{K O}$ mouse skin (A) and distal interphalangeal (DIP) tissues (B). Six-month-old ihTNFtg or ihTNFtg/Fhl $2^{K O}$ mice were left untreated (cntr) or stimulated with $1 \mathrm{mg} / \mathrm{mL}$ doxycycline (Dox) for 3 weeks, after which immune cells present in the skin and

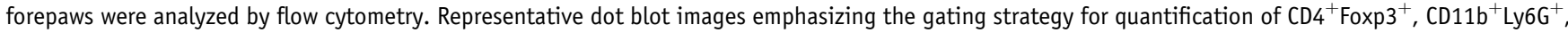

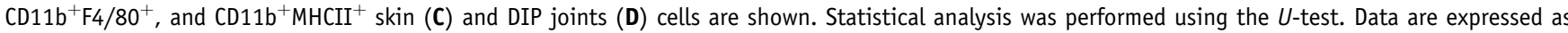
means \pm SEM (A and $\mathbf{B}) . n=5$ to 6 mice per group $(\mathbf{A}$ and $\mathbf{B})$. ${ }^{*} P<0.05,{ }^{*} P<<0.01$, and ${ }^{* * * P}<0.001$.

fluorescein di- $\beta$-D-galactopyranoside in isolated $F h l 2^{-/-}$ macrophages or X-Gal in $F h l 2^{-/-}$chondrocytes of finger tissue sections revealed a decreased $\beta$-galactosidase activity in these cells under sustained TNF induction (Figure 3, C and D). The results indicate that Fhl2 expression is reduced in response to the TNF stimulus, which is in full agreement with our previous data showing that proinflammatory cytokines suppress Fhl 2 expression ${ }^{4}$ and with the concept that Fhl 2 counteracts inflammatory reactions.
Several cytokines that are commonly linked to psoriasis and arthritis, like IL-1 (Illb), IL-6 (Il6), IL-23 (Il23a), or interferon- $\gamma$ (Ifng), were strongly and significantly upregulated after Dox stimulation in ihTNFtg and ihTNFtg/ $F h l 2^{K O}$ mice, but not regulated between the genotypes (Figure 3, A and B). Consistent with increased numbers of Tregs and macrophages, an augmented expression of Foxp3 (Foxp3) and especially of IL-10 (IllO) and CCL2 (Ccl2) cytokines was observed in skin and joints of ihTNFtg/Fhl2 ${ }^{K O}$ 
A

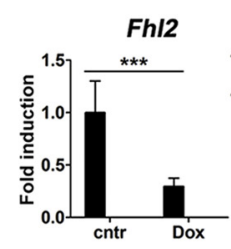

Skin

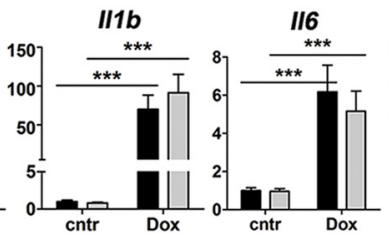

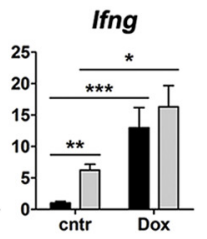

B
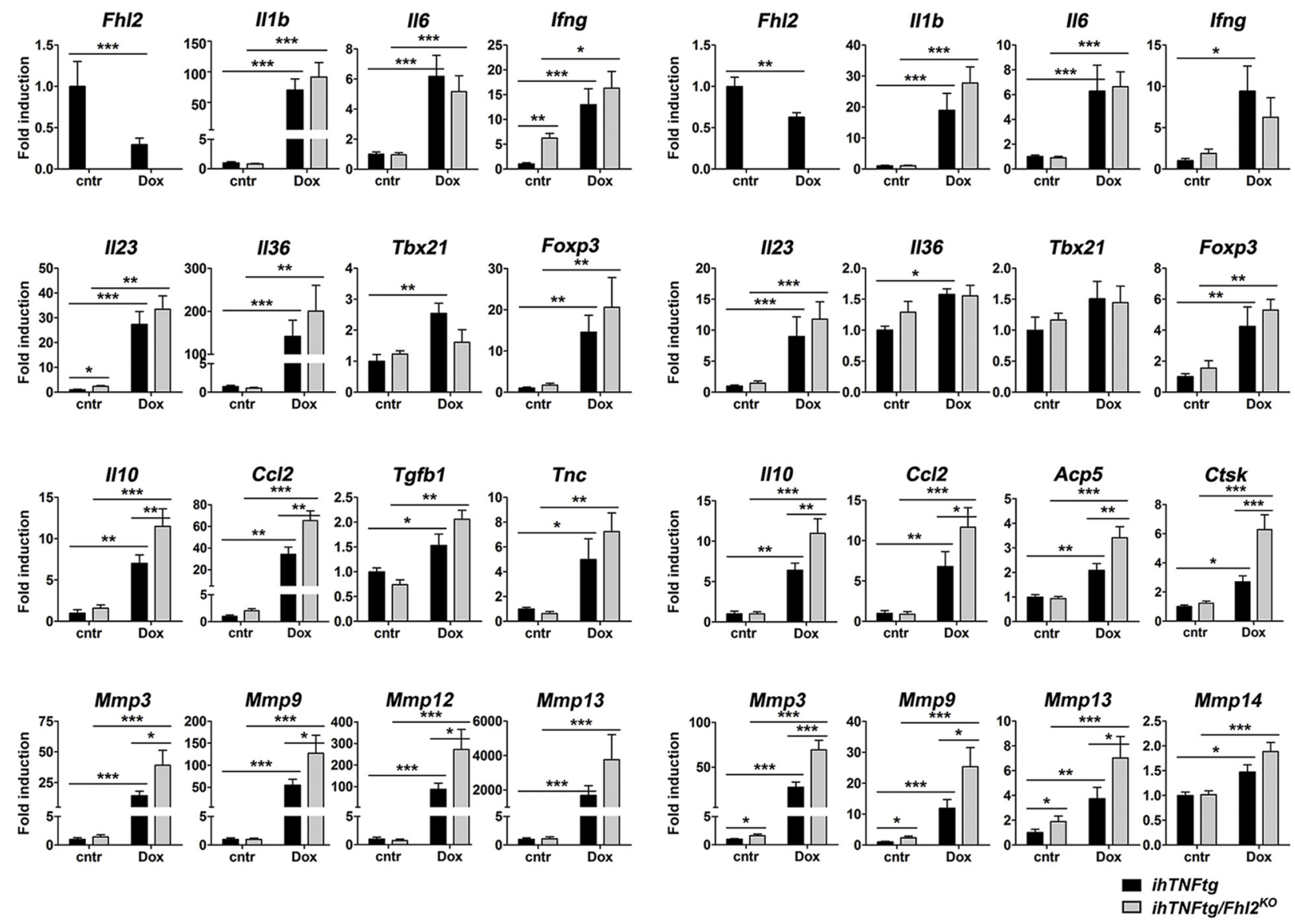

C
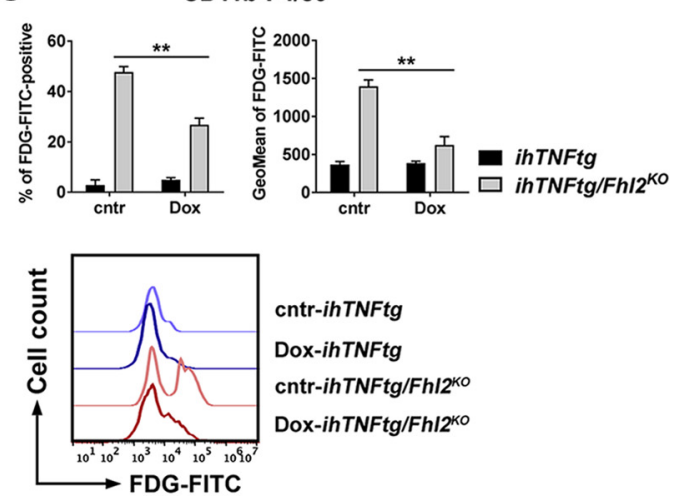

cntr-ihTNFtg

Dox-ihTNFtg

cntr-ihTNFtg/Fhl2 ${ }^{\text {Ko }}$

Dox-ihTNFtg/Fhl2

D

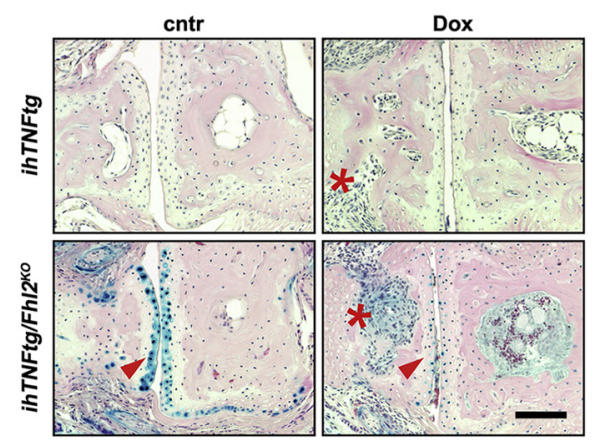

Fhl2/ $\beta$-gal in chondrocytes

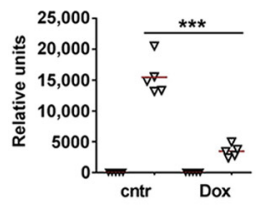

v inTNFtg

$\nabla$ ihTNFtg/Fh/2 ${ }^{\text {KO }}$

Figure 3 A and B: Cytokine and chemokine status of ihTNFtg and ihTNFtg/Fhl $2^{K O}$ mouse skin (A) and distal interphalangeal (DIP) tissues (B). Sixmonth-old ihTNFtg and ihTNFtg/Fhl2 ${ }^{K O}$ mice received either drinking water only (cntr) or drinking water containing $1 \mathrm{mg} / \mathrm{mL}$ doxycycline (Dox) for 3 weeks, and gene expression in skin (A) or forepaw (B) samples was analyzed by TaqMan quantitative real-time RT-PCR. The amount of mRNA in control ihTNFtg mice was assigned a value of 1 . Statistical analysis was performed using one-way analysis of variance, followed by the Newman-Keuls test. C: Flow cytometry analysis of freshly isolated skin single-cell suspension for macrophage marker (CD11b and F4/80) and Fhl2/B-Gal expression. Cells were incubated with fluorescein di- $\beta$-D-galactopyranoside (FDG), and the number of fluorescein isothiocyanate (FITC)-positive cells was measured. The top left panel represents the percentage of FDG-FITC-positive macrophages, and the top right panel represents the GeoMean values of FDG-FITC. The bottom panel shows a flow cytometric analysis of FDG-FITC intensity in macrophages from a representative Cntr or Dox-stimulated ihTNFtg and ihTNFtg/Fhl2 ${ }^{K O}$ mouse. D: DIP joints were stained with X-Gal to mark the Fhl2/ $\beta$-Gal protein (light blue) and counterstained with hematoxylin and eosin (H\&E; dark blue and red). Note the strong staining of chondrocytes for Fhl2/ $\beta$-Gal in Cntr and the weak staining in Dox-treated ihTNFtg/Fhl ${ }^{K O}$ mice (left panel). Asterisks mark the pannus-like tissue, and arrowheads mark the Fhl2/ $\beta$-Gal-positive chondrocytes. The right panel shows the relative intensity of Fhl2/ $\beta$-Gal staining in chondrocytes of Cntr and Dox ihTNFtg/Fhl2 ${ }^{K O}$ mice. The light blue area was always assessed to the total cartilage tissues area of the joint. Mean values (red lines) of four phalanges for each mouse are shown. Slides without H\&E counterstaining were used herein. Data are expressed as means \pm SEM $(\mathbf{A}-\mathbf{C}) . n=6$ to 10 animals per group (A and $\mathbf{B}) ; n=5$ animals per group $(\mathbf{C}) .{ }^{*} P<0.05,{ }^{*} P<0.01$, and ${ }^{* * *} P<0.001$. Scale bar $=100 \mu \mathrm{m}(\mathbf{D})$. 
mice. Hence, cytokines activating and attracting Tregs and macrophages were much more strongly expressed in ihTNFtg/Fhl2 ${ }^{K O}$ mice after Dox stimulation (Figure 3). In accordance with a stronger psoriatic arthritis phenotype in ihTNFtg/Fhl2 ${ }^{K O}$ mice, there was a significantly higher expression of MMPs in skin and joints of Fhl2-deficient mice compared to ihTNFtg animals. Proteases responsible for bone destruction, like tartrate-resistant acid phosphatase (Acp5) and cathepsin $\mathrm{K}$ (Ctsk), were also much more strongly expressed in joints of Dox-stimulated ihTNFtg/Fhl2 ${ }^{K O}$ mice. Interestingly, variations in MMP expression were seen between the affected skin and joints. Although MMP13 (Mmp13) showed the highest up-regulation under induction of TNF in the skin, MMP3 (Mmp3) was the most abundant MMP in DIP joints. Remarkably, some MMPs [eg, MMP3 (Mmp3), MMP9 (Мmp9), or MMP13 (Mmp13)] already showed a significantly higher expression in untreated control joints of $i h T N F t g / F h l 2^{K O}$ mice compared to Fhl2-containing ihTNFtg mice (Figure 3B). These results, together with increased infiltration of TNF-affected tissues in $F h l 2^{K O}$ mice and the fact that sustained high levels of TNF down-regulate Fhl2 expression in diverse cell types, altogether highlight Fhl2 as a critical regulator of autoimmune diseases.

\section{Serum Levels of Soluble Cytokines in ihTNFtg and ihTNFtg/Fhl2 ${ }^{K O}$ Mice after Dox Stimulation}

To determine whether the development of psoriatic arthritis in these mice causes a systemic up-regulation of proinflammatory cytokines, the levels of cytokines in serum of Dox-stimulated ihTNFtg and ihTNFtg/Fhl2 ${ }^{K O}$ mice were compared to non-stimulated control mice using enzymelinked immunosorbent assay style binding experiments. Fifteen different cytokines linked to inflammation, including those that showed a strong Dox-dependent upregulation by quantitative real-time RT-PCR (IL-1, IL-23, and interferon- $\gamma$ ), were analyzed. Among those, only IL6, IL-10, and CCL2 showed increased levels in serum after Dox stimulation and were higher in ihTNFtg/Fhl2 ${ }^{\mathrm{KO}}$ compared with ihTNFtg mice. However, the differences were not statistically significant, probably because of the low number of independently tested animals and the variations in the values (Figure 4A). Nevertheless, increased values of IL-10 and CCL2 cytokines in the serum of ihTNFtg/Fhl2 ${ }^{K O}$ mice match well with increased numbers of Tregs and macrophages in the skin and digits. Surprisingly, soluble human TNF, being strongly increased after Dox stimulation in both mouse lines, showed significantly higher levels in ihTNFtg/Fhl2 ${ }^{K O}$ mice than in ihTNFtg mice (Figure 4A). Even more, control ihTNFtg/Fhl2 ${ }^{K O}$ animals also displayed higher levels of hTNF in serum. Consistent with stronger psoriatic arthritis in $i h T N F t g / F h l 2^{K O}$ mice and higher levels of hTNF in their serum, these animals also produced greater amounts of S100A8/A9 alarmins. S100A8/A9 heterodimers are usually expressed and secreted by activated keratinocytes and monocytes as well
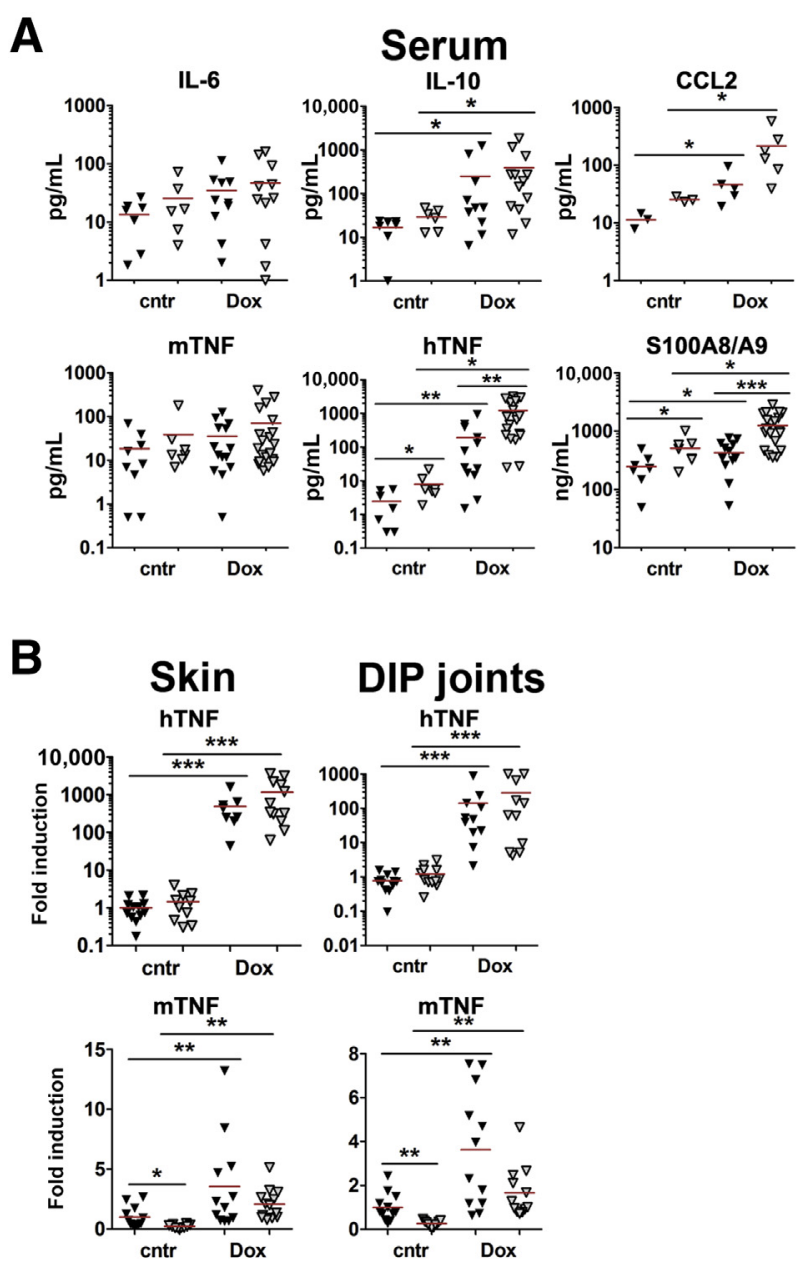

Figure 4 Inflammatory cytokines in serum of ihTNFtg (closed triangles) and ihTNFtg/Fhl2 ${ }^{K O}$ (open triangles) mice after doxycycline stimulation. A: Sixmonth-old ihTNFtg or ihTNFtg/Fhl2 ${ }^{K O}$ mice were left untreated (cntr) or stimulated with $1 \mathrm{mg} / \mathrm{mL}$ doxycycline (Dox) for 3 weeks, after which the amount of cytokines in sera was measured by either classic enzyme-linked immunosorbent assay [human tumor necrosis factor (hTNF), murine tumor necrosis factor (mTNF), and S100A8/A9] or the AYOXXA (IL-6 and IL-10) or Legendplex [chemokine (C-C motif) ligand (CCL2)] method. B: Gene expression in skin or forepaw samples from mice shown in $\mathbf{A}$ was analyzed by TaqMan quantitative real-time RT-PCR. Mean values (red lines) per group are shown. Statistical analysis was performed using the $U$-test. ${ }^{*} P<0.05,{ }^{* *} P<0.01$, and ${ }^{* * *} P<0.001$.

as neutrophils at sites of inflammation and TNF, and S100A8/A9 are mutually up-regulated in a functional feedback loop. ${ }^{20}$

To assess whether increased levels of soluble hTNF in ihTNFtg/Fhl2 ${ }^{K O}$ mice resulted from enhanced transcription of the human $T N F$ transgene, the amount of $h T N F$ mRNA in skin and digit samples of ihTNFtg and ihTNFtg/ $F h l 2^{K O}$ mice before and after Dox stimulation were compared. The transcription of the $h T N F$ transgene was strongly enhanced in both tissue types after Dox stimulation, but surprisingly no differences between ihTNFtg and ihTNFtg/Fhl2 ${ }^{\mathrm{KO}}$ mice could be measured (Figure 4B). Hence, the increased hTNF serum level in ihTNFtg/ $F h l 2^{K O}$ mice is most probably driven by posttranscriptional active mechanisms. 
Fhl2 Deficiency Boosts the Adam17-Directed Shedding of Surface-Bound hTNF

Newly synthesized TNF molecules are expressed as $26-\mathrm{kDa}$ large transmembrane proteins. The soluble 17-kDa TNF cytokine is released by the membrane-bound protein with disintegrin and metalloprotease activity Adam17, also called TNF- $\alpha$-converting enzyme. ${ }^{21}$ Fhl2 physically interacts with the cytosolic tail of the transmembrane Adam $17^{22}$ and was proposed to influence Adam 17 function. Hence, we studied whether the increased amount of soluble hTNF in ihTNFtg/ $F h l 2^{K O}$ mice might be a result of enhanced shedding activity by Adam 17 because of the absence of Fhl2 protein. Freshly isolated skin cells from intact ihTNFtg and ihTNFtg/Fhl2 ${ }^{K O}$ mice were stimulated with Dox in the presence or absence of Adam 17 inhibitor TMI- $1 .{ }^{19}$ Subsequently, the relative amounts of hTNF molecules on the surface of TNF-expressing cells were measured by flow cytometry. As shown in Figure 5, A and B, non-Dox-stimulated keratinocytes hardly expressed hTNF on their surfaces, but after Dox stimulation, both ihTNFtg and ihTNFtg/Fhl2 ${ }^{K O}$ derived keratinocytes were strongly positive for membrane-bound hTNF. Interestingly, ihTNFtg/Fhl2 ${ }^{K O}$ cells expressed fewer hTNF molecules on their surface than $i h T N F$ keratinocytes. However, in the presence of the Adam17 inhibitor TMI-1, the amount of surfacebound hTNF increased. The increase was TMI-1 concentration dependent and began from $10 \mathrm{mmol} / \mathrm{L}$ of the inhibitor, but no differences in surface-expressed hTNF molecules were visible anymore between ihTNFtg and ihTNFtg/Fhl2 ${ }^{K O}$ cells (Figure 5C). Thus, the Adam17-mediated shedding of surface TNF was increased in the absence of Fhl2. Notably, the synthesis of Adam 17 transcripts was not altered, neither under Fhl 2 deficiency nor on Dox stimulation (Figure 5D), indicating that the sheddase activity of Adam 17 is increased in the absence of its binding partner Fhl2.

\section{Discussion}

In this work, we demonstrate that Fhl2 most certainly has anti-inflammatory activity. Using a mouse model for psoriatic arthritis, the TNF-inducible ihTNFtg mouse, we show that in animals lacking Fhl2, prolonged high induction of TNF induces a much more severe disease phenotype than in wild-type mice expressing Fhl2. We further show that Fhl2 suppresses the sheddase activity of Adam17, thus reducing the release of membrane-bound TNF and declining serum levels of TNF- $\alpha$, the key inflammatory cytokine. Finally, we illustrate that on TNF-mediated induction of psoriatic arthritis, a similar kind of inflammation develops in affected skin and joint tissues.

On development of psoriatic arthritis, the expression of Fhl2 was significantly down-regulated in both skin and DIP joint tissues, including tissue infiltrating immune cells (Figure 3). ${ }^{4}$ This additionally underlines the major result of this work, which was the finding that in the absence of Fhl2,
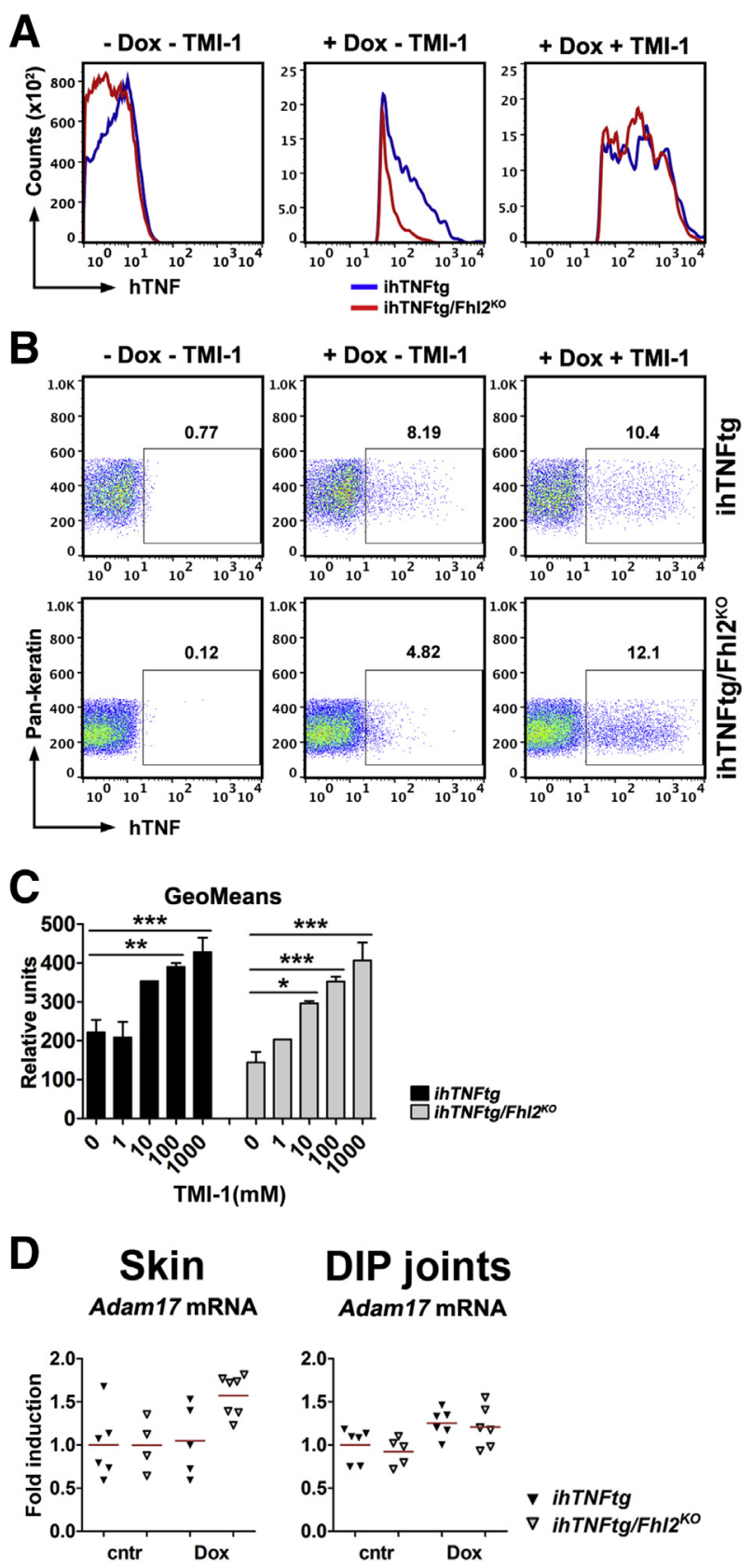

Figure 5 Fhl2 deficiency encourages the Adam17 responsive release of surface-bound human tumor necrosis factor (hTNF). A-C: Keratinocytes were isolated from control ihTNFtg and ihTNFtg/Fh $22^{K O}$ mice and cultivated in vitro for 4 hours in either Dulbecco's modified Eagle's medium plus 10\% fetal calf serum alone or in medium containing $20 \mu \mathrm{g} / \mathrm{mL}$ doxycycline (Dox) and different amounts of the Adam17 inhibitor TMI-1. Then, cells were stained for surface-bound hTNF and intracellular pan-keratins and analyzed by flow cytometry. A and B: The distribution of hTNF-positive cells. Keratinocytes incubated with no Dox and no inhibitor (left panels), with Dox only (middle panels), and with Dox and $100 \mathrm{mmol} / \mathrm{L}$ of TMI-1 inhibitor (right panels) are shown as histogram (A) and dot-plot (B) images. Representative dot blot images emphasize the gating strategy for quantification of hTNF $\alpha$ positive cells (B). C: The geometric mean fluorescence intensity of surface-expressed hTNF. D: Skin and distal interphalangeal (DIP) joint tissues of 6-month-old control (cntr) or 3-week-long Dox-stimulated (Dox) ihTNFtg and ihTNFtg/Fhl2 ${ }^{K O}$ mice were analyzed for Adam 17 transcripts by TaqMan quantitative real-time RT-PCR. Results of single mice with mean values per groupare presented (red lines). Data are expressed as means $\pm \mathrm{SEM}(\mathrm{C}) . n=4$ repeated experiments (C). ${ }^{*} P<0.05,{ }^{* *} P<0.01$, and ${ }^{* * *} P<0.001$ (U-test). 
TNF-mediated development of psoriatic arthritis is stimulated. Under normal situations in vivo, most tissues, except the heart, show only moderate or no expression of Fhl2.,23 However, as an early response gene protein, Fhl2 is rapidly up-regulated in injured tissues during their recovery. Profibrotic cytokines, such as TGF- $\beta$ and sphingosine 1-phosphate, induce Fhl2 expression, whereas proinflammatory cytokines, such as IL- $1 \beta$, IL- 6 , or TNF- $\alpha$, inhibit its expression (this work). ${ }^{4,24,25}$ The precise role of Fhl2 in distinct cell types during TNF-induced inflammation is only partially resolved so far and needs further investigation. Nevertheless, our results are in good agreement with published data and are consistent with the conclusion that Fhl2 is up-regulated during tissue regeneration, but down-regulated during tissue-damaging chronic inflammations. ${ }^{4,5,9}$ Interestingly, the closest Fhl2 homologs, Fhl1 and Fhl3, showed a different behavior in the skin and DIP joints of ihTNFtg mice to sustained TNF induction (Supplemental Figure S3), indicating that they may not act in concert with Fhl2 during inflammation. However, this needs to be defined in future experiments.

Fhl2 is a multifunctional adaptor molecule and, as such, is involved in the regulation of different signaling pathways and gene transcription. It interacts with integrins, kinases, structural proteins, and transcription factors, thereby modulating different cellular activities. Depending on interaction partners, Fhl2 may even exert opposite functions, ${ }^{2,3}$ a property characteristic for many adaptor proteins. ${ }^{26} \mathrm{Fhl} 2$ has been reported to be a potent inducer of the epithelial-mesenchymal transition and to contribute significantly to the invasion of tumor cells. ${ }^{12,27}$ Furthermore, Fhl2 deficiency has been shown to lead to impaired wound healing because of defective matrix assembly, cell migration, and contraction of granulation tissue. ${ }^{9,28}$ In lungs, the absence of Fhl2 caused a constantly enhanced inflammation status that was further increased after application of the fibrosis-inducing agent bleomycin. ${ }^{5}$ In liver, Fhl2 deficiency results in delayed tissue regeneration because of the insufficient release of proliferation-supporting cytokines by Kupffer cells. ${ }^{7}$ Finally, Fhl2 plays an important role in bone remodeling by modulating the activity of osteoclasts and osteoblasts. ${ }^{29-31}$ Therefore, Fhl2 seems to be an important component not only in tissue regeneration and in inflammation but also in controlling the expression of matrix metalloproteinases that orchestrate the wound healing and inflammatory functions at various levels. Herein, Fhl2 may modulate the activation of inflammatory mediators via MMP regulation, the recruitment of inflammatory cells, or the processing of extracellular matrix proteins. ${ }^{32,33}$ Uncontrolled high expression of MMPs may also easily run into tissue destruction, and Fhl 2 inhibits that by preventing sustained activation of the p38 mitogen-activated protein kinase pathway, ${ }^{4}$ which is crucial for induction of MMPs by proinflammatory cytokines. ${ }^{34}$

Recently, we showed that Fhl2 inhibits the TNF$\alpha-$ mediated transcriptional induction of proarthritic MMPs via modulation of the p38 mitogen-activated protein kinase pathway, playing an essential role in the repair of inflammatory tissue damage during rheumatoid arthritis. ${ }^{4}$ Herein, we describe a new function of Fhl2 in psoriatic arthritis. We show that in addition to suppression of MMP transcription, Fhl2 also inhibits the Adam17-mediated release of membrane-bound TNF. Although TNF is also biologically active as a transmembrane protein, its soluble form has a much greater stimulatory outcome, as it can reach and bind to cells of almost all tissues. Although increased levels of the TNF cytokine lead to many irregularities in the organism, the most prominent disorders are arthritis and psoriasis. ${ }^{1}$ Adam 17 is recognized for a while as the major TNF sheddase. ${ }^{21}$ However, whether Fhl2 regulates Adam17-mediated surface release of TNF is unknown so far, although the interaction between Fhl2 and Adam 17 was described. ${ }^{22}$ Herein, we show that the absence of Fhl2 leads to enhanced proteolytic ectodomain shedding of the cell surface TNF cytokine, which finally results in an increased psoriatic arthritis disorder.

Given that the absence of Fhl2 results in higher levels of soluble hTNF, the increased infiltration of skin and DIP joints by activated macrophages and Tregs is not so surprising. Indeed, psoriatic arthritis in ihTNFtg mice is predominantly a TNF-mediated disorder, which leads to infiltration of affected tissues by macrophages, but not by $\mathrm{T}$ helper cell 17 or $\gamma \delta \mathrm{T}$ lymphocytes, despite high induction of IL-23. ${ }^{14}$ Furthermore, the predominantly TNF-mediated immune disease concurrently induces activation and attraction to inflamed sites of Tregs, most likely to compensate the tissue-destructive effect of macrophages. ${ }^{35}$ These data are consistent with low or absent induction of lymphocyte-activating transcription factors T-bet (Tbx21), GATA4 (Gata3), or RORgt (Rorc) (Figure 3). ${ }^{14}$ The emergent high levels of soluble TNF in Fhl2 knockout mice induce, in turn, increased transcription of MMPs, the induction of which is further favored by the absence of the p38 mitogen-activated protein kinase pathway inhibitor Fhl2. ${ }^{4}$ The increased manifestation of MMPs, along with CCL2 and IL-10, in ihTNFtg/Fhll2 ${ }^{K O}$ mice (ie, proteins intimately involved in activation and attraction of immune cells at inflammation) fits well with increased infiltration of skin and joints with macrophages and Tregs and with the more severe disease in Fhl2 knockout mice. Interestingly, in ihTNFtg/RAG1 ${ }^{K O}$ mice, the increased infiltration of psoriatic skin by macrophages because of the absence of inflammation inhibitory Tregs also coincided with increased expression of MMP9 and CCL2. ${ }^{14}$ Whether Fhl2 inhibits, similar to MMP transcription, the TNF-mediated expression of CCL2 and IL-10 is not clear yet, although a clear reduction of Fhl2 expression in macrophages on TNF burden was demonstrated in this work. It is also unclear whether the increased infiltration of immune cells into diseased tissues of $i h T N F t g / F h l 2^{K O}$ mice might be caused, in addition to increased levels of MMPs and cytokines, by altered integrin or other protein functions, the association of which with Fhl2 is disturbed in Fhll2 ${ }^{K O}$ mice. Although we 
cannot exclude that altered cytoskeletal rearrangement or cell-cell and cell-matrix interactions might play a role in increased tissue infiltration in ihTNFtg/Fhl2 ${ }^{K O}$ mice, the question probably has to be analyzed separately for distinct cell types, because Fhl2, as a multifaceted adaptor protein, might both support and inhibit migration of cells. ${ }^{9,13}$

An additional interesting observation of this work is that the type and kind of inflammation in different types of tissue, as skin and joints, were actually similar during the TNF-mediated disorder. Both skin and DIP joints showed a strong up-regulation of the same range of cytokines, such as IL-1 $\beta$, IL-6, or IL-23. Also, the pattern of immune cells that infiltrated the affected skin and DIP joints was similar. Only the relative amount of cytokine induction and immune cells in the skin was much higher than in DIP joints. The cause for that, however, might rather have technical than physiological reasons. It was easier to localize the inflammation and to gain large numbers of single cells for flow cytometry analyses from skin samples than from digits. In the last case, always complete forepaws were digested, although the major inflammation was localized in DIP joints, as histological analysis indicated (Supplemental Figure S2).

In summary, we showed herein that Fhl2 inhibits the cleavage of the TNF ectodomain by Adam17. The decreased $\mathrm{TNF}$ release, in turn, reduces the systemic induction of proinflammatory cytokines and MMPs, thus dampening the development of inflammation and tissue degradation. Besides this, Fhl2 blocks the transcription of MMPs, additionally contributing toward minimizing the inflammation. However, on sustained TNF expression, Fhl 2 itself is down-regulated, which promotes the expansion of inflammation or turning it into chronification. Hence, the results of this work not only confirmed the anti-inflammatory properties of Fhl 2 but also disclosed a novel site of the versatile adaptor protein Fhl2, anticipating the emerging inflammation by impeding the Adam17-mediated release of TNF- $\alpha$. Altogether, our results indicate that FHL2 has a strong regulatory effect on tissue damage in vivo and provides a promising new target in the treatment of psoriasis and rheumatoid arthritis.

\section{Supplemental Data}

Supplemental material for this article can be found at http://dx.doi.org/10.1016/j.ajpath.2017.07.015.

\section{References}

1. Kollias G: TNF pathophysiology in murine models of chronic inflammation and autoimmunity. Semin Arthritis Rheum 2005, 34:3-6

2. Johannessen M, Moller S, Hansen T, Moens U, Van Ghelue M: The multifunctional roles of the four-and-a-half-LIM only protein FHL2. Cell Mol Life Sci 2006, 63:268-284

3. Kleiber K, Strebhardt K, Martin BT: The biological relevance of FHL2 in tumour cells and its role as a putative cancer target. Anticancer Res 2007, 27:55-61

4. Wixler V, Cromme C, Retser E, Meyer LH, Smyth N, Muhlenberg K, Korb-Pap A, Koers-Wunrau C, Sotsios Y, Bassel-Duby R, Baeten D,
Tak PP, Niederreiter B, Redlich K, Bertrand J, Skryabin BV, Ludwig S, Pap T: FHL2 regulates the resolution of tissue damage in chronic inflammatory arthritis. Ann Rheum Dis 2015, 74:2216-2223

5. Alnajar A, Nordhoff C, Schied T, Chiquet-Ehrismann R, Loser K, Vogl T, Ludwig S, Wixler V: The LIM-only protein FHL2 attenuates lung inflammation during bleomycin-induced fibrosis. PLoS One 2013, 8:e81356

6. Kurakula K, Vos M, Logiantara A, Roelofs JJ, Nieuwenhuis MA, Koppelman GH, Postma DS, Brandsma CA, Sin DD, Bosse Y, Nickle DC, van Rijt LS, de Vries CJ: Deficiency of FHL2 attenuates airway inflammation in mice and genetic variation associates with human bronchial hyper-responsiveness. Allergy 2015, 70:1531-1544

7. Dahan J, Nouet Y, Jouvion G, Levillayer F, Adib-Conquy M, CassardDoulcier AM, Tebbi A, Blanc F, Remy L, Chen J, Cairo S, Werts C, Si-Tahar M, Tordjmann T, Buendia MA, Wei Y: LIM-only protein FHL2 activates NF-kappaB signaling in the control of liver regeneration and hepatocarcinogenesis. Mol Cell Biol 2013, 33:3299-3308

8. Kirfel J, Pantelis D, Kabba M, Kahl P, Roper A, Kalff JC, Buettner R: Impaired intestinal wound healing in Fhl2-deficient mice is due to disturbed collagen metabolism. Exp Cell Res 2008, 314:3684-3691

9. Wixler V, Hirner S, Muller JM, Gullotti L, Will C, Kirfel J, Gunther T, Schneider H, Bosserhoff A, Schorle H, Park J, Schule R, Buettner R: Deficiency in the LIM-only protein Fhl2 impairs skin wound healing. J Cell Biol 2007, 177:163-172

10. Goltz D, Hittetiya K, Gevensleben H, Kirfel J, Diehl L, Meyer R, Buttner R: Loss of the LIM-only protein Fhl2 impairs inflammatory reaction and scar formation after cardiac ischemia leading to better hemodynamic performance. Life Sci 2016, 151:348-358

11. Chu PH, Yeh LK, Lin HC, Jung SM, Ma DH, Wang IJ, Wu HH, Shiu TF, Chen J: Deletion of the FHL2 gene attenuating neovascularization after corneal injury. Invest Ophthalmol Vis Sci 2008, 49:5314-5318

12. Gullotti L, Czerwitzki J, Kirfel J, Propping P, Rahner N, Steinke V, Kahl P, Engel C, Schule R, Buettner R, Friedrichs N: FHL2 expression in peritumoural fibroblasts correlates with lymphatic metastasis in sporadic but not in HNPCC-associated colon cancer. Lab Invest 2011, 91:1695-1705

13. Konig K, Diehl L, Rommerscheidt-Fuss U, Golletz C, Quast T, Kahl P, Kolanus W, Knolle P, Buettner R, Heukamp LC: Four-and-a-half LIM domain protein 2 is a novel regulator of sphingosine 1-phosphate receptor 1 in CCL19-induced dendritic cell migration. J Immunol 2010, 185:1466-1475

14. Leite Dantas R, Masemann D, Schied T, Bergmeier V, Vogl T, Loser K, Brachvogel B, Varga G, Ludwig S, Wixler V: Macrophagemediated psoriasis can be suppressed by regulatory $\mathrm{T}$ lymphocytes. J Pathol 2016, 240:366-377

15. Retser E, Schied T, Skryabin BV, Vogl T, Kanczler JM, Hamann N, Niehoff A, Hermann S, Eisenblatter M, Wachsmuth L, Pap T, van Lent PL, Loser K, Roth J, Zaucke F, Ludwig S, Wixler V: Doxycycline-induced expression of transgenic human tumor necrosis factor alpha in adult mice results in psoriasis-like arthritis. Arthritis Rheum 2013, 65:2290-2300

16. Katsantoni EZ, Anghelescu NE, Rottier R, Moerland M, Antoniou M, de Crom R, Grosveld F, Strouboulis J: Ubiquitous expression of the rtTA2S-M2 inducible system in transgenic mice driven by the human hnRNPA2B1/CBX3 CpG island. BMC Dev Biol 2007, 7:108

17. Shimada A, Komatsu K, Nakashima K, Poschl E, Nifuji A: Improved methods for detection of beta-galactosidase (lacZ) activity in hard tissue. Histochem Cell Biol 2012, 137:841-847

18. Kong Y, Shelton JM, Rothermel B, Li X, Richardson JA, BasselDuby R, Williams RS: Cardiac-specific LIM protein FHL2 modifies the hypertrophic response to beta-adrenergic stimulation. Circulation 2001, 103:2731-2738

19. Zhang Y, Xu J, Levin J, Hegen M, Li G, Robertshaw H, Brennan F, Cummons T, Clarke D, Vansell N, Nickerson-Nutter C, Barone D, Mohler K, Black R, Skotnicki J, Gibbons J, Feldmann M, Frost P, Larsen G, Lin LL: Identification and characterization of 4-[[4-(2butynyloxy)phenyl]sulfonyl]-N-hydroxy-2,2-dimethyl-(3S) 
thiomorpholinecar boxamide (TMI-1), a novel dual tumor necrosis factoralpha-converting enzyme/matrix metalloprotease inhibitor for the treatment of rheumatoid arthritis. J Pharmacol Exp Ther 2004, 309:348-355

20. Vogl T, Tenbrock K, Ludwig S, Leukert N, Ehrhardt C, van Zoelen MA, Nacken W, Foell D, van der Poll T, Sorg C, Roth J: Mrp8 and Mrp14 are endogenous activators of Toll-like receptor 4, promoting lethal, endotoxin-induced shock. Nat Med 2007, 13:1042-1049

21. Black RA, Rauch CT, Kozlosky CJ, Peschon JJ, Slack JL, Wolfson MF, Castner BJ, Stocking KL, Reddy P, Srinivasan S, Nelson N, Boiani N, Schooley KA, Gerhart M, Davis R, Fitzner JN, Johnson RS, Paxton RJ, March CJ, Cerretti DP: A metalloproteinase disintegrin that releases tumour-necrosis factor-alpha from cells. Nature 1997, 385:729-733

22. Canault M, Tellier E, Bonardo B, Mas E, Aumailley M, JuhanVague I, Nalbone G, Peiretti F: FHL2 interacts with both ADAM-17 and the cytoskeleton and regulates ADAM-17 localization and activity. J Cell Physiol 2006, 208:363-372

23. Chu PH, Bardwell WM, Gu Y, Ross J Jr, Chen J: FHL2 (SLIM3) is not essential for cardiac development and function. Mol Cell Biol 2000 , 20:7460-7462

24. Joos H, Albrecht W, Laufer S, Reichel H, Brenner RE: IL-1beta regulates FHL2 and other cytoskeleton-related genes in human chondrocytes. Mol Med 2008, 14:150-159

25. Muller JM, Metzger E, Greschik H, Bosserhoff AK, Mercep L, Buettner R, Schule R: The transcriptional coactivator FHL2 transmits Rho signals from the cell membrane into the nucleus. EMBO J 2002, 21:736-748

26. Ayllon J, Garcia-Sastre A: The NS1 protein: a multitasking virulence factor. Curr Top Microbiol Immunol 2015, 386:73-107

27. Zhang W, Wang J, Zou B, Sardet C, Li J, Lam CS, Ng L, Pang R, Hung IF, Tan VP, Jiang B, Wong BC: Four and a half LIM protein 2
(FHL2) negatively regulates the transcription of E-cadherin through interaction with Snail1. Eur J Cancer 2011, 47:121-130

28. Park J, Will C, Martin B, Gullotti L, Friedrichs N, Buettner R, Schneider H, Ludwig S, Wixler V: Deficiency in the LIM-only protein FHL2 impairs assembly of extracellular matrix proteins. FASEB J 2008, 22:2508-2520

29. Bai S, Kitaura H, Zhao H, Chen J, Muller JM, Schule R, Darnay B, Novack DV, Ross FP, Teitelbaum SL: FHL2 inhibits the activated osteoclast in a TRAF6-dependent manner. J Clin Invest 2005, 115 : $2742-2751$

30. Gunther T, Poli C, Muller JM, Catala-Lehnen P, Schinke T, Yin N, Vomstein S, Amling M, Schule R: Fhl2 deficiency results in osteopenia due to decreased activity of osteoblasts. EMBO J 2005, 24: 3049-3056

31. Lai CF, Bai S, Uthgenannt BA, Halstead LR, McLoughlin P, Schafer BW, Chu PH, Chen J, Otey CA, Cao X, Cheng SL: Four and half lim protein 2 (FHL2) stimulates osteoblast differentiation. J Bone Miner Res 2006, 21:17-28

32. Loffek S, Schilling O, Franzke CW: Series "matrix metalloproteinases in lung health and disease": biological role of matrix metalloproteinases: a critical balance. Eur Respir J 2011, 38:191-208

33. Nissinen L, Kahari VM: Matrix metalloproteinases in inflammation. Biochim Biophys Acta 2014, 1840:2571-2580

34. Sondergaard BC, Schultz N, Madsen SH, Bay-Jensen AC, Kassem M, Karsdal MA: MAPKs are essential upstream signaling pathways in proteolytic cartilage degradation: divergence in pathways leading to aggrecanase and MMP-mediated articular cartilage degradation. Osteoarthr Cartil 2010, 18:279-288

35. Gatzka M: Skin under Tnf influence: how regulatory T cells work against macrophages in psoriasis. J Pathol 2017, 241:3-5 